\title{
Calcium influx at the tip of growing root-hair cells of Arabidopsis thaliana
}

\author{
John W. Schiefelbein ${ }^{1 *}$, Al Shipley ${ }^{2}$, and Paul Rowse ${ }^{1}$ \\ 1 Department of Biology, University of Michigan, Ann Arbor, MI 48109, USA \\ ${ }^{2}$ Marine Biological Laboratory, Woods Hole, MA 02543, USA
}

Received 9 December 1991; accepted 22 February 1992

\begin{abstract}
The role of extracellular $\mathrm{Ca}^{2+}$ in root-hair tip growth has been investigated in Arabidopsis thaliana (L.) Heynh. Root-hair length was found to be dependent on the concentration of $\mathrm{Ca}^{2+}$ in the growth medium, with maximum length achieved at $\left[\mathrm{Ca}^{2+}\right]$ of $0.3-3.0 \mathrm{mM}$. Using a non-intrusive calcium-specific vibrating microelectrode, an extracellular $\mathrm{Ca}^{2+}$ gradient was detected at the tips of individual growing root-hair cells. The direction of the gradient indicated a net influx of $\mathrm{Ca}^{2+}$ into root-hair cells. No gradient was detected near the sides of the root hairs or at the tips of non-growing root hairs. When root hairs were exposed to the $\mathrm{Ca}^{2+}$-channel blocker nifedipine, tip growth stopped and the extracellular $\mathrm{Ca}^{2+}$ gradient was abolished. These results indicate that $\mathrm{Ca}^{2+}$ influx through plasma-membrane $\mathrm{Ca}^{2+}$ channels is required for normal root-hair tip growth.
\end{abstract}

Key words: Arabidopsis (calcium and root-hair growth) - Calcium channel - Root hair - Tip growth - Vibrating probe, $\mathrm{Ca}^{2+}$-specific

\section{Introduction}

Calcium ions play a key role in many cellular processes in higher plants, including cell division, cell expansion, and cytoplasmic streaming (for reviews, see Hepler and Wayne 1985; Kauss 1987). The importance of $\mathrm{Ca}^{2+}$ in plant cell expansion has been particularly well-documented in studies of tip-growing cells, such as pollen tubes and root hairs. These cells are suitable for studying cell expansion because they are easily accessible, grow rapidly, and expansion is limited to a specific region of the cell (for reviews, see Schnepf 1986; Heath 1990).

The importance of $\mathrm{Ca}^{2+}$ in pollen-tube tip growth has been demonstrated by several lines of evidence. Growth

* To whom correspondence should be addressed; FAX (313) 747-0884

Abbreviation $: \mathrm{APW}=$ artificial pond water of pollen tubes in vitro requires $\mathrm{Ca}^{2+}$ in the medium at a concentration of $10^{-2}-10^{-6} \mathrm{M}$ (Brewbaker and Kwack 1963; Picton and Steer 1983). When growing pollen tubes are subjected to a sudden decrease in the external $\mathrm{Ca}^{2+}$ concentration or to $\mathrm{Ca}^{2+}$-channel blockers (e.g. nifedipine), the tubes display a sharply reduced growth rate and form swellings at the tip of the tube (Reiss and Herth 1985). In addition, growing pollen tubes rapidly accumulate extracellular ${ }^{45} \mathrm{Ca}$ at the tip region (Jaffe et al. 1975). A variety of methods have been used to detect and measure an internal $\mathrm{Ca}^{2+}$ gradient in growing pollen tubes, with the highest $\mathrm{Ca}^{2+}$ concentration at the tip (Reiss and Herth 1978; Reiss et al. 1983, 1985; Reiss and Nobiling 1986; Nobiling and Reiss 1987). Electrophysiological studies with an extracellular vibrating microelectrode have shown that ion currents flow into the tip of the growing pollen tube (Jaffe and Nuccitelli 1974; Weisenseel et al. 1975), and the recent development of a calcium-specific vibrating probe has led to the demonstration that a large portion of the inward ion current is carried by $\mathrm{Ca}^{2+}$ (Kuhtreiber and Jaffe 1990).

Although root-hair elongation is morphologically similar to pollen-tube growth, relatively little is known about the physiology of root-hair growth or the role of $\mathrm{Ca}^{2+}$ in this process. Root-hair length has been shown to be sensitive to the concentration of $\mathrm{Ca}^{2+}$ in the growth medium, indicating that extracellular $\mathrm{Ca}^{2+}$ is necessary for elongation (Cormack 1949; Burström 1952; Tanaka and Woods 1972, 1973; Ewens and Leigh 1985). In addition, an internal tip-to-base $\mathrm{Ca}^{2+}$ gradient has been detected in growing root hairs by using the fluorescent $\mathrm{Ca}^{2+}$ indicators chlorotetracycline (for membranebound calcium; Reiss and Herth 1979) and fura-2 AM (for cytoplasmic calcium; Clarkson et al. 1988). Finally, ion currents entering growing root-hair tips have been detected (Weisenseel et al. 1979; Miller et al. 1986), although the contribution of $\mathrm{Ca}^{2+}$ to the currents is not known.

Recently, root-hair development has attracted attention as a potentially useful model system for studying plant cell expansion. This has been, in part, a conse- 
quence of the realization that molecular-genetic approaches can be applied to this process (Schiefelbein and Somerville 1990). However, in order to interpret the results of molecular-genetic experiments fully, there is a need for a better understanding of the physiology of root-hair development. With this goal in mind, we have examined the role of external $\mathrm{Ca}^{2+}$ on root-hair growth in Arabidopsis thaliana. In this paper, we show that roothair elongation in Arabidopsis is sensitive to the concentration of external $\mathrm{Ca}^{2+}$ and to the $\mathrm{Ca}^{2+}$-channel blocker nifedipine. In addition, we have used a calciumspecific vibrating microelectrode (Kuhtreiber and Jaffe 1990) to detect extracellular $\mathrm{Ca}^{2+}$ gradients around individual root-hair cells.

\section{Material and methods}

Plant material and growth conditions. Seeds of Arabidopsis thaliana (L.) Heynh. (ecotype Columbia; source: G. Redei, University of Missouri, Columbia, USA) were surface-sterilized, and grown on agarose-solidified media under continuous illumination, as described in Schiefelbein and Somerville (1990). The growth medium used in these studies, artificial pond water (APW), consisted of $0.1 \mathrm{mM} \mathrm{KCl}, 0.1 \mathrm{mM} \mathrm{CaCl}_{2}, 0.1 \mathrm{mM} \mathrm{MgCl}, 0.5 \mathrm{mM} \mathrm{NaCl}, 1 \mathrm{mM}$ 2(N-morpholino)ethanesulfonic acid $(\mathrm{pH} 5.6$ ), and $0.2 \mathrm{mM}$ $\mathrm{Na}_{2} \mathrm{SO}_{4}$.

To examine the effect of various external $\mathrm{Ca}^{2+}$ concentrations, seeds were distributed on modified APW media containing different amounts of $\mathrm{CaCl}_{2}$ and solidified with $0.6 \%$ agarose. External $\mathrm{Ca}^{2+}$ concentrations below $0.1 \mathrm{mM}$ were controlled by using a $\mathrm{Ca}^{2+}$. EGTA (ethylene glycol-bis( $\beta$-aminoethyl ether)-N,N,N',N'tetraaceticacid) buffer system (Chang et al. 1988). Agarose was used as the solidifying agent rather than agar, because agar was found to contain appreciable levels of $\mathrm{Ca}^{2+}$ as well as an unknown contaminant that inhibits root-hair growth (data not shown). Roothair length was measured $4 \mathrm{~d}$ after seed germination, using hairs that developed from mature portions of the root in contact with the agarose surface.

Vibrating-probe experiments. The vibrating-microelectrode studies were conducted at the National Vibrating Probe Facility, Marine Biological Laboratories, Woods Hole, Mass., USA. The construction and use of the calcium-specific electrode has been described by Kuhtreiber and Jaffe (1990). In the present experiments, seeds were placed on APW medium containing $0.3 \mathrm{mM} \mathrm{CaCl}_{2}$ solidified with $1.5 \%$ agarose and incubated in a horizontal orientation. At this agarose concentration, most roots grow along the surface of the medium and do not penetrate into the latter. After 4-6 d of growth, $30 \mathrm{ml}$ of APW liquid medium was applied over the surface of the solid medium. After $1 \mathrm{~h}$, the entire Petri dish was placed on the microscope stage and subjected to vibrating-probe analyses. In the standard experiments, the calcium-specific microelectrode was vibrated perpendicular to the cell surface and positioned such that it was approx. $3 \mu \mathrm{m}$ away from the root-hair surface at its nearest vibration point. Since the excursion value used in these experiments was $9.6 \mu \mathrm{m}$, the probe vibrated between a point approx. $3 \mu \mathrm{m}$ from the surface of the root hair to a point approx. $12.6 \mu \mathrm{m}$ from the surface of the root hair. The reference values were obtained by vibrating the probe at positions at least $100 \mu \mathrm{m}$ away from the root-hair tip. The growth of the root hairs during the vibratingprobe measurements was monitored by time-lapse video-tape recordings.

Nifedipine treatments. A $10 \mathrm{mM}$ nifedipine (Sigma Chemical Co., St. Louis, Mo., USA) stock solution was diluted into the APW liquid medium in the Petri dishes to a final concentration of $100 \mu \mathrm{M}$. The growth-rate and $\mathrm{Ca}^{2+}$-gradient measurements were made on individual root hairs at various timepoints from $20 \mathrm{~min}$ before to $120 \mathrm{~min}$ after the introduction of nifedipine. In the intervals between measurements, the Petri dishes were covered with aluminum foil to protect the nifedipine, which is light-sensitive. Some of the Petri plates containing nifedipine-treated plants were subsequently uncovered, placed under the growth lights for $6 \mathrm{~h}$ and then compared with covered, control plants.

\section{Results}

Effect of external $\mathrm{Ca}^{2+}$ on root-hair length. To examine the effect of external $\mathrm{Ca}^{2+}$ on the growth of root hairs of Arabidopsis, seedlings were grown on agarose-solidified APW media containing free- $\mathrm{Ca}^{2+}$ concentrations from 0.001 to $10 \mathrm{mM}$. The results of this dose-response experiment are shown in Fig. 1. Root-hair length increased as the external $\mathrm{Ca}^{2+}$ concentration was increased from 0.003 to $0.3 \mathrm{mM}$. Maximum root-hair length of approx. $0.8 \mathrm{~mm}$ was obtained at $\mathrm{Ca}^{2+}$ concentrations between 0.3 and $3 \mathrm{mM}$.

The effects of low $\mathrm{Ca}^{2+}$ concentrations on root-hair length were shown to be attributable to the reduction in $\mathrm{Ca}^{2+}$ and not $\mathrm{Cl}^{-}$. No change in root-hair length was observed when the $\mathrm{Cl}^{-}$concentration was reduced by changing the $\mathrm{NaCl}$ concentration in the APW medium from $0.5 \mathrm{mM}$ to $0.3 \mathrm{mM}$ (data not shown). Furthermore, similar reductions in root-hair length have been observed when Arabidopsis plants were grown on other plant growth media deprived of $\mathrm{Ca}^{2+}$ (data not shown).

Although the length of root hairs was affected by changes in the external $\mathrm{Ca}^{2+}$ concentration, there was no noticeable effect on root-hair cell shape. However, root growth was affected by the $\mathrm{Ca}^{2+}$ treatments of 0.010 , 0.003 , and $0.001 \mathrm{mM}$. Under these conditions, the roots were shorter than normal and appeared to be unable to respond normally to gravity (data not shown).

Vibrating probe analyses. The studies described above indicated that the elongation of Arabidopsis root hairs requires extracellular $\mathrm{Ca}^{2+}$. To examine the possibility that external $\mathrm{Ca}^{2+}$ is taken up by growing root hairs, we used a calcium-specific vibrating microelectrode (Kuh-

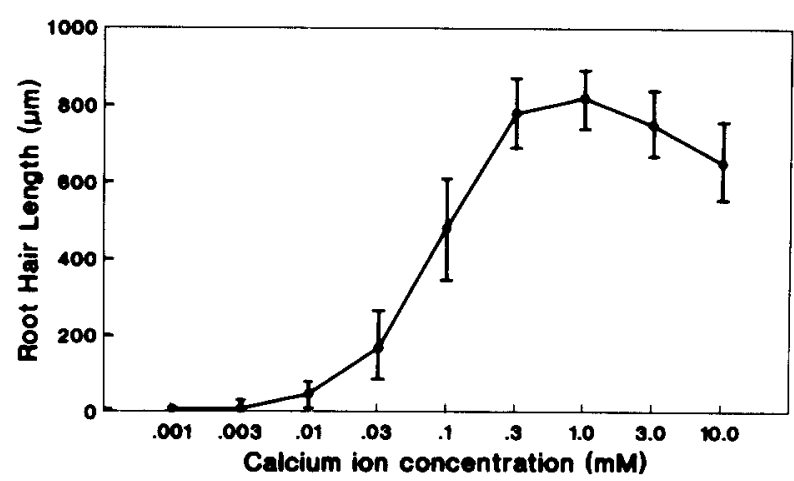

Fig. 1. Effect of external $\mathrm{Ca}^{2+}$ on root-hair length in Arabidopsis. Seedlings were grown in modified APW medium containing various concentrations of $\mathrm{CaCl}_{2}$, and root-hair length was measured after $4 \mathrm{~d}$ of growth. A Ca${ }^{2+}$-EGTA buffer system was used for $\mathrm{Ca}^{2+}$ concentrations below $0.1 \mathrm{mM}$. For each datum point, $n=40$ 
Table 1. Calcium-specific ion flux at the tips of growing and non-growing root hairs of Arabidopsis ${ }^{\mathrm{a}}$

\begin{tabular}{llll}
\hline Root-hair type & $\begin{array}{l}\text { Growth rate } \\
\left(\mu \mathrm{m} \cdot \mathrm{min}^{-1}\right)\end{array}$ & $\begin{array}{l}\text { Voltage } \\
(\mu \mathrm{V})\end{array}$ & $\begin{array}{l}\mathrm{Ca}^{2+} \mathrm{flux}^{\mathrm{b}} \\
\left(\mathrm{pmol} \cdot \mathrm{cm}^{-2} \cdot \mathrm{s}^{-1}\right)\end{array}$ \\
\hline $\begin{array}{l}\text { Growing hairs } \\
(n=28)\end{array}$ & $1.3 \pm 0.3$ & $11.2 \pm 1.2$ & $4.4 \pm 0.5$ \\
$\begin{array}{l}\text { Fully mature hairs } \\
(n=21)\end{array}$ & $0.1 \pm 0.2$ & $0.8 \pm 0.8$ & $0.3 \pm 0.3$ \\
$\begin{array}{l}\text { Hairs that stopped growing } \\
\text { during examination } \\
(n=8)\end{array}$ & $0.2 \pm 0.2$ & $0.7 \pm 0.6$ & $0.2 \pm 0.2$ \\
\hline
\end{tabular}

a Measurements include $\pm \mathrm{SE}$

b Vibrating-probe measurements were made by positioning the probe $3 \mu \mathrm{m}$ in front of the root-hair tip and vibrating parallel to the growth axis treiber and Jaffe 1990) in attempts to detect extracellular $\mathrm{Ca}^{2+}$ gradients around individual root hairs. Because the probe is noninvasive, it was possible to measure the root-hair growth rate and $\mathrm{Ca}^{2+}$ gradients simultaneously. The $\mathrm{Ca}^{2+}$ concentration used in these studies $(0.3 \mathrm{mM})$ was chosen as a compromise between the desire to allow maximum root-hair elongation and the need to maintain the $\mathrm{Ca}^{2+}$ concentration as low as possible to obtain maximum sensitivity of the calcium-probe measurements (for further discussion, see Kuhtreiber and Jaffe 1990).

In the first set of experiments, the calcium probe was positioned directly in front of tips of individual root hairs and vibrated parallel to the axis of growth. When growing root hairs were examined in this manner, a $\mathrm{Ca}^{2+}$. specific voltage difference was detected, indicating a difference in the concentration of $\mathrm{Ca}^{2+}$, and therefore a $\mathrm{Ca}^{2+}$ concentration gradient, between the two points of vibration (Table 1). The voltage difference reflected a lower $\mathrm{Ca}^{2+}$ concentration at the vibration point closer to the root-hair tip, implying that $\mathrm{Ca}^{2+}$ was removed from the liquid media by the growing cells.

When growing root hairs of different lengths (from 50 to $500 \mu \mathrm{m}$ ) were examined, no significant difference was detected in the magnitude of the $\mathrm{Ca}^{2+}$ gradients or in the rate of hair elongation. Under these experimental conditions, root hairs of Arabidopsis were found to elongate at a relatively constant rate of approx. $1.3 \mu \mathrm{m} \cdot \mathrm{min}^{-1}$ (Table 1).

$\mathrm{A} \mathrm{Ca}^{2+}$ gradient was not detected when the tips of non-growing root hairs (mature hairs) were examined with the vibrating probe (Table 1). In addition, there were several hairs that had stopped growing (reached their mature length) during the period of time they were being examined. In each of these cases, the cessation of growth was accompanied by a loss of the extracellular $\mathrm{Ca}^{2+}$ gradient (Table 1).

Extracellular $\mathrm{Ca}^{2+}$ gradients were examined in more detail by mapping the gradients around the tip and side walls of individual growing root hairs. The position of the probe varied in each of these measurements, but the direction of vibration was always perpendicular to the nearest cell surface. The results of this analysis showed that the $\mathrm{Ca}^{2+}$ gradient is steepest at the root-hair tip and is not detectable at the root-hair side walls (Fig. 2). The same results were obtained from a different set of experi-

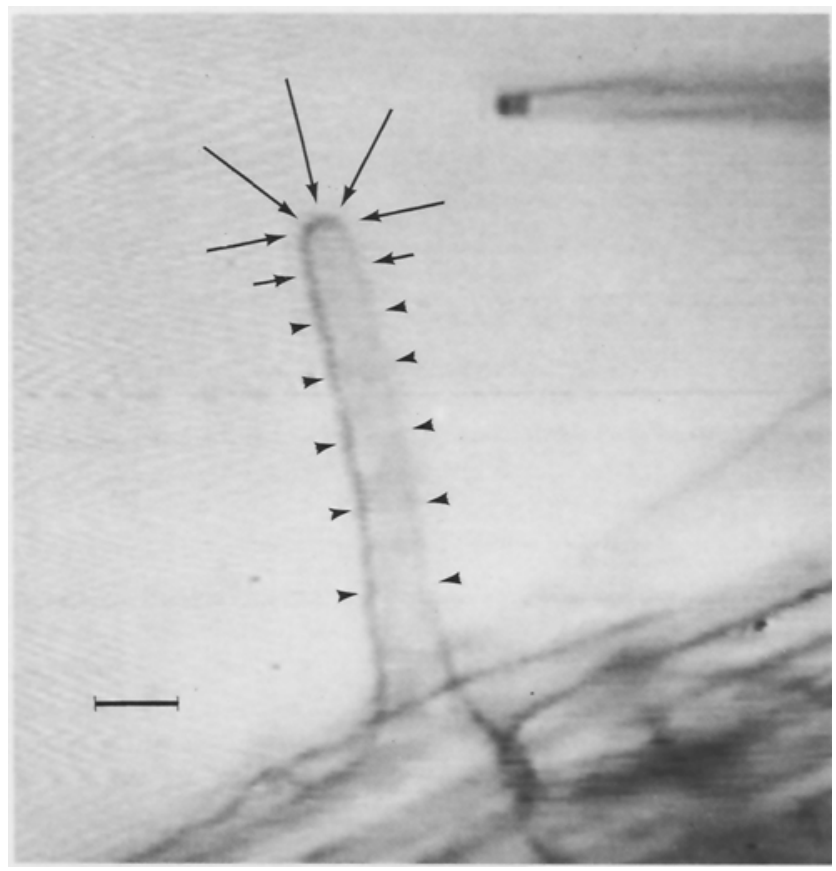

Fig. 2. Calcium gradients around growing root hairs of Arabidopsis. The relative $\mathrm{Ca}^{2+}$-flux measurements at various positions around growing root hairs are indicated by the lengths of the arrows. The direction of the $\mathrm{Ca}^{2+}$ gradient is indicated by the direction of the arrow (from a site of high $\mathrm{Ca}^{2+}$ to low $\mathrm{Ca}^{2+}$ ). Arrowheads mean that no significant $\mathrm{Ca}^{2+}$ flux was detected. At each position, the calcium-specific probe was vibrated perpendicular to the cell surface and at a distance of 3-12.6 $\mu \mathrm{m}$ from the surface. For each probe position, $n=12$. The probe is shown at the upper right portion of the figure. $\mathrm{X} 400$; bar $=10 \mu \mathrm{m}$

ments in which the calcium probe was vibrated in a single position and the root hair was allowed to "grow" past it (Fig. 3). In these experiments, the probe was vibrated perpendicular to the axis of growth and positioned approx. $8 \mu \mathrm{m}$ from the center of the tip (at its nearest vibration point) to prevent the growing hair from colliding with the probe. Because of this arrangement, the distance between the calcium probe and different sites on the root-hair cell surface was not constant. Therefore, the magnitude of the $\mathrm{Ca}^{2+}$ currents detected near the roothair tip (position 0 ) was an underestimate of the true relative value. Nevertheless, the results of these two sets of experiments indicate that $\mathrm{Ca}^{2+}$ is removed from the 


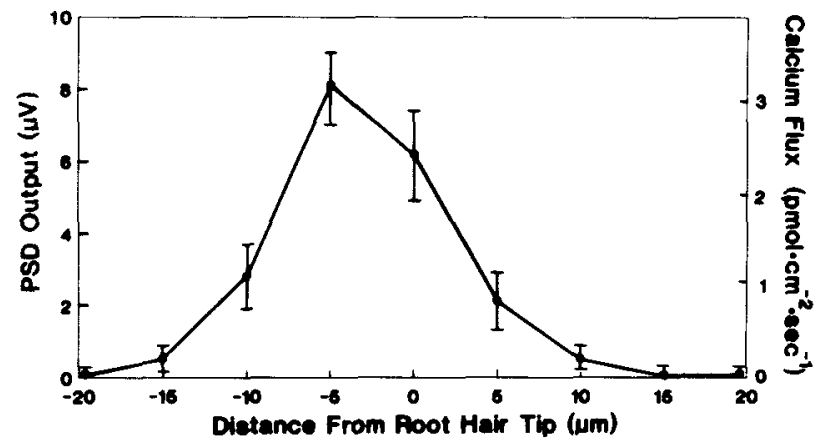

Fig. 3. Calcium-ion flux at various positions relative to the tip of an Arabidopsis root hair. The calcium probe was vibrated at a fixed position and the root hair was allowed to grow "past" the probe. The distances with a positive value are in front of the hair tip and those with a negative value are behind the tip (along the side wall of the cell). Because of the design of this experiment, the distance from the probe to the root-hair cell wall is not constant at all positions. $P S D=$ phase-sensitive detection

media by the tips of growing root-hair cells. In neither of these experiments was a $\mathrm{Ca}^{2+}$ gradient detected along the root-hair surface that might indicate a net $\mathrm{Ca}^{2+}$ efflux from the root-hair.

The vibrating probe was also positioned near epidermal cells in the hair-forming zone of the root to try to detect $\mathrm{Ca}^{2+}$ gradients that might precede the emergence of root hairs. No marked $\mathrm{Ca}^{2+}$ gradient was detected along the length of these epidermal cells. Calcium-ion gradients were only detected when the probe was placed near the portion of an epidermal cell that had already produced a noticeable "bulge", i.e. had initiated a root hair.

Effect of the $\mathrm{Ca}^{2+}$-channel blocker nifedipine. To examine the effect of an organic $\mathrm{Ca}^{2+}$-channel blocker on roothair growth and the observed $\mathrm{Ca}^{2+}$ gradients, Arabidopsis seedlings were treated with nifedipine $(100 \mu \mathrm{M})$. Nifedipine acts by binding to plasma-membrane $\mathrm{Ca}^{2+}$ channels to prevent $\mathrm{Ca}^{2+}$ entry into cells (Reiss and Herth 1985). One hour after the introduction of nifedipine, root-hair elongation ceased and the extracellular $\mathrm{Ca}^{2+}$ gradient was abolished (Table 2).

The nifedipine treatments also caused changes in the shape of the root hairs; the most common abnormality was the formation of an enlarged tip region (Fig. 4). After longer exposures to nifedipine, some hairs also formed branches. These morphological changes were

Table 2. Effect of nifedipine on growth and calcium-specific ion flux in root hairs of Arabidopsis ${ }^{a}$

\begin{tabular}{lll}
$\begin{array}{l}\text { Time after nifedipine } \\
\text { treatment }(\mathrm{min})\end{array}$ & $\begin{array}{l}\text { Growth rate } \\
\left(\mu \mathrm{m} \cdot \mathrm{min}^{-1}\right)\end{array}$ & $\begin{array}{l}\mathrm{Ca}^{2+} \mathrm{flux}^{\mathrm{b}} \\
\left(\mathrm{pmol} \cdot \mathrm{cm}^{-2} \cdot \mathrm{s}^{-1}\right)\end{array}$ \\
\hline 0 & $1.4 \pm 0.3$ & $4.1 \pm 0.3$ \\
5 & $1.2 \pm 0.3$ & $3.8 \pm 0.4$ \\
60 & $0.1 \pm 0.2$ & $0.2 \pm 0.4$
\end{tabular}

a Measurements were made on the same root hairs before and after treatment with $100 \mu \mathrm{M}$ nifedipine $(n=14)$ and include \pm SE

${ }^{b}$ Calcium flux was determined by positioning the probe $3 \mu \mathrm{m}$ in front of the root-hair tip and vibrating parallel to the growth axis

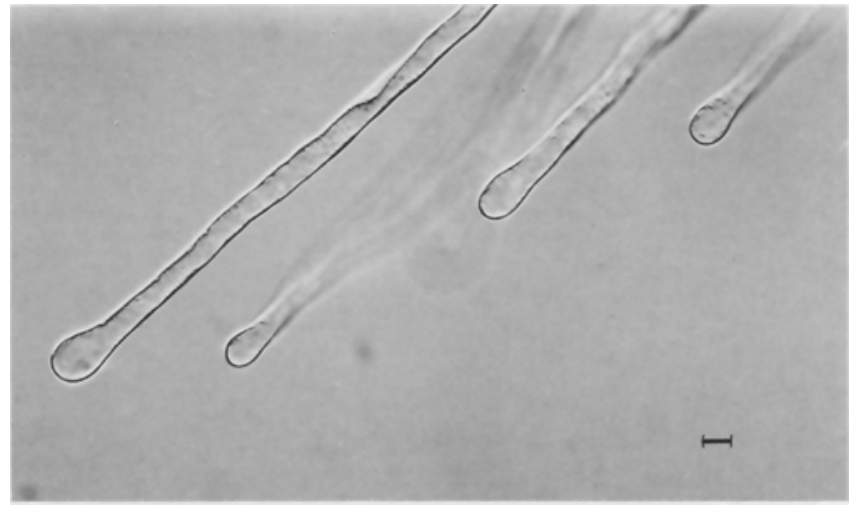

Fig. 4. Morphology of root hairs of Arabidopsis following nifedipine treatment. Seedlings were exposed to $100 \mu \mathrm{M}$ nifedipine in APW for $1 \mathrm{~h}$. Note the bulging root-hair tips. X400; bar $=10 \mu \mathrm{m}$

only observed in hairs that had been actively growing; mature hairs were not affected by the nifedipine treatments. In addition, when treated plants were exposed to light, root-hair growth resumed in some of the hairs, implying that inactivation of the nifedipine reversed the growth inhibition.

\section{Discussion}

The results of this study show that external $\mathrm{Ca}^{2+}$ is required for normal root-hair elongation and that an extracellular $\mathrm{Ca}^{2+}$ gradient exists at the tips of growing root hairs. $\mathrm{A} \mathrm{Ca}^{2+}$ gradient was not detected at the tips of non-growing root hairs nor was one detected near the side walls of growing root hairs. The presence of this gradient indicates that the growing root-hair tip acts as a "sink" for external $\mathrm{Ca}^{2+}$. Because treatment with the $\mathrm{Ca}^{2+}$-channel blocker nifedipine abolished the $\mathrm{Ca}^{2+}$ gradient, it follows that the gradient is the result of $\mathrm{Ca}^{2+}$ uptake through plasma-membrane $\mathrm{Ca}^{2+}$ channels localized at the root-hair tip. This $\mathrm{Ca}^{2+}$ influx may be maintained by the continual fusion of $\mathrm{Ca}^{2+}$-channel-containing vesicles at the tip, assuming that the $\mathrm{Ca}^{2+}$ channels have a short functional lifetime, as has been suggested to account for similar observations in other tip-growing systems (Schnepf 1986; Heath 1990).

The precise role of the $\mathrm{Ca}^{2+}$ taken up by the growing root hairs is not understood. It is possible that some of the $\mathrm{Ca}^{2+}$ serves to bind to polysaccharides in the growing cell wall. However, the observation of enlarged and branched tips in nifedipine-treated root hairs indicates that $\mathrm{Ca}^{2+}$ is taken up into the cytoplasm and is required, in some way, to maintain polarized growth. Some of its possible intracellular roles include: $\mathrm{Ca}^{2+}$ regulation of vesicle secretion; directed organelle transport; cytoskeleton arrangement; and $\mathrm{Ca}^{2+}$ - and calmodulin-dependent enzyme activities.

A related unresolved issue is the ultimate fate of the $\mathrm{Ca}^{2+}$ taken up by the root-hair cells. Since no outwarddirected $\mathrm{Ca}^{2+}$ flux was detected at any point along the surface of growing root hairs, the root hair must deal with the excess $\mathrm{Ca}^{2+}$ in some other way, perhaps by sequestering it within a cellular compartment (Steer 1989). However, we cannot rule out an alternative possi- 
bility, namely that $\mathrm{Ca}^{2+}$ efflux occurs over a large portion of the root-hair cell membrane and the resulting diffuse, outward-directed $\mathrm{Ca}^{2+}$ flux was too small to be detected by the calcium probe.

The $\mathrm{Ca}^{2+}$ gradient detected in this study indicates a net influx of $\mathrm{Ca}^{2+}$ into the growing root-hair tip. However, it is likely that $\mathrm{Ca}^{2+}$ is also secreted during vesicle fusion with the plasma membrane (Njus et al. 1986). Therefore, the magnitude of the inward-directed $\mathrm{Ca}^{2+}$ flux detected in our experiments is probably an underestimate of the actual magnitude of the $\mathrm{Ca}^{2+}$ influx.

While the present study provides strong evidence for a role for external $\mathrm{Ca}^{2+}$ in root-hair elongation, the importance of external $\mathrm{Ca}^{2+}$ in root-hair initiation is not as clear. At external $\mathrm{Ca}^{2+}$ concentrations below $0.010 \mathrm{mM}$, root hairs did not form on most epidermal cells, indicating that external $\mathrm{Ca}^{2+}$ is required for initiation. However, extracellular $\mathrm{Ca}^{2+}$ currents were not detected prior to the formation of a root hair primordium. It may be that a relatively small $\mathrm{Ca}^{2+}$ influx is required for root-hair initiation, and this was not detectable in the present experiments.

In general, the results obtained in our study are similar to the observations of $\mathrm{Ca}^{2+}$ influx during pollen-tube growth (see Introduction). In each cell type, growth is affected by suboptimal levels of $\mathrm{Ca}^{2+}$ and by nifedipine. In addition, the extracellular $\mathrm{Ca}^{2+}$ gradient discovered at the tips of growing root hairs has also been reported at growing pollen-tube tips (Kuhtreiber and Jaffe 1990), although the pollen-tube gradients have not been mapped in as much detail. Interestingly, the magnitude of the $\mathrm{Ca}^{2+}$ flux at the root-hair tip (approx. $4.4 \mathrm{pmol}$. $\left.\mathrm{cm}^{-1} \cdot \mathrm{s}^{-1}\right)$ is similar to that measured at the pollen-tube tip (approx. $4.0 \mathrm{pmol} \cdot \mathrm{cm}-1 \cdot \mathrm{s}-1$; Kuhtreiber and Jaffe 1990).

Some of the $\mathrm{Ca}^{2+}$-related alterations in root-hair morphology observed in our study are similar to the phenotypes of root-hair mutants of Arabidopsis reported by Schiefelbein and Somerville (1990). For example, some of these mutants produce short hairs and hairs with swellings and branches, which are similar to the hairs produced by plants grown in low concentrations of $\mathrm{Ca}^{2+}$ or treated with nifedipine. It is therefore possible that some of these root-hair mutants possess defects in $\mathrm{Ca}^{2+}$ uptake or in $\mathrm{Ca}^{2+}$-dependent processes at the root-hair tip. The examination of extracellular $\mathrm{Ca}^{2+}$ gradients in these mutant root hairs may serve to define the defect in root hair development further.

We thank L.F. Jaffe, W. Kuhtreiber and A. Miller of the National Vibrating Probe Facility, Marine Biological Laboratory, Woods Hole, Mass., USA for their technical assistance and helpful discussions. We also thank Liam Dolan, Martin Steer, and Susan Ford for helpful discussions. This research was supported by National Science Foundation grant PCM-9004568.

\section{References}

Brewbaker, J.L., Kwack, B.H. (1963) The essential role of calcium ion in pollen germination and pollen tube growth. Am. J. Bot. 50, 859-865

Burström, H. (1952) Studies on growth and metabolism of roots. VIII. Calcium as a growth factor. Physiol. Plant. 5, 391-402
Chang, D., Hsieh, P.S., Dawson, D.C. (1988) Calcium: a program in BASIC for calculating the composition of solutions with specified free concentrations of calcium, magnesium, and other divalent cations. Comput. Biol. Med. 18, 351-366

Clarkson, D.T., Brownlee, C., Ayling, S.M. (1988) Cytoplasmic calcium measurements in intact higher plant cells: results from fluorescence ratio imaging of fura-2. J. Cell Sci. 91, 71-80

Cormack, R.G.H. (1949) The development of root hairs in angiosperms. Bot. Rev. 15, 583-612

Ewens, M., Leigh, R.A. (1985) The effect of nutrient solution composition on the length of root hairs of wheat (Triticum aestivum L.). J. Exp. Bot. 36, 713-724

Heath, I.B., ed. (1990) Tip growth in plant and fungal cells. Academic Press, New York

Hepler, P.K., Wayne, R.O. (1985) Calcium and plant development. Annu. Rev. Plant Physiol. 36, 397-439

Jaffe, L.F., Nuccitelli, R. (1974) An ultrasensitive vibrating probe for measuring steady extracellular currents. J. Cell Biol. 63, 614-628

Jaffe, L., Weisenseel, M.H., Jaffe, L.F. (1975) Calcium accumulations within the growing tips of pollen tubes. J. Cell Biol. 67, 488-492

Kauss, H. (1987) Some aspects of calcium-dependent regulation in plant metabolism. Annu. Rev. Plant Physiol. 38, 47-72

Kuhtreiber, W.M., Jaffe, L.F. (1990) Detection of extracellular calcium gradients with a calcium-specific vibrating electrode. J. Cell Biol. 110, 1565-1573

Miller, A.L., Raven, J.A., Sprent, J.I., Weisenseel, M.H. (1986) Endogenous ion currents traverse growing roots and root hairs of Trifolium repens. Plant Cell Environ. 9, 79-83

Njus, D., Kelley, P.M., Harnadek, G.J. (1986) Bioenergetics of secretory vesicles. Biochim. Biophys. Acta 853, 237-265

Nobiling, R., Reiss, H.D. (1987) Quantitative analysis of calcium gradients and activity in growing pollen tubes of Lilium longiflorum. Protoplasma 139, 20-24

Picton, J.M., Steer, M.W. (1983) Evidence for the role of $\mathrm{Ca}^{2+}$ ions in tip extension in pollen tubes. Protoplasma 115, 11-17

Reiss, H.-D., Herth, W. (1978) Visualization of the $\mathrm{Ca}^{2+}$-gradient in growing pollen tubes of Lilium longiflorum with chlorotetracycline fluorescence. Protoplasma 97, 373-377

Reiss, H.-D., Herth, W. (1979) Calcium gradients in tip growing plant cells visualized by chlorotetracycline fluorescence. Planta 146, 615-621

Reiss, H.-D., Herth, W. (1985) Nifedipine-sensitive calcium channels are involved in polar growth of lily pollen tubes. J. Cell Sci. 76, 247-254

Reiss, H.-D., Nobiling, R. (1986) Quin-2 fluorescence in pollen tubes: distribution of free cytoplasmic calcium. Protoplasma 131, 244-246

Reiss, H.-D., Herth, W., Schnepf, E., Nobiling, R. (1983) The tip-to-base calcium gradient in pollen tubes of Lilium longiflorum measured by proton-induced X-ray emission (PIXE). Protoplasma 115, 153-159

Reiss, H.-D., Herth, W., Nobiling, R. (1985) Development of membrane- and calcium-gradients during pollen germination of Lilium longiflorum. Planta 163, 84-90

Schiefelbein, J.W., Somerville, C. (1990) Genetic control of root hair development in Arabidopsis thaliana. Plant Cell 2, 235-243

Schnepf, E. (1986) Cellular polarity. Annu. Rev. Plant Physiol. 37, $23-47$

Steer, M.W. (1989) Calcium control of pollen tube tip growth. Biol. Bull. 176 Suppl., 18-20

Tanaka, Y., Woods, F.W. (1972) Root and root hair growth in relation to supply and internal mobility of calcium. Bot. Gaz. 133, 29-34

Tanaka, Y., Woods, F.W. (1973) Root and root hair growth of oats: replaceability of calcium. Can. J. Bot. 51, 1655-1659

Weisenseel, M.H., Nuccitelli, R., Jaffe, L.F. (1975) Large electrical currents traverse growing pollen tubes. J. Cell Biol. 66, 556-567

Weisenseel, M.H., Dorn, A., Jaffe, L.F. (1979) Natural $\mathrm{H}^{+}$currents traverse growing roots and root hairs of barley (Hordeum vulgare L.). Plant Physiol. 64, 512-518 